\title{
Counseling for the Wilderness Athlete and Adventurer During a Preparticipation Evaluation for Preparation, Safety, and Injury Prevention
}

\author{
Justin Mark J. Young, MD; Aaron D. Campbell, MD, MHS; Kate K. Raastad, BS \\ From the Department of Family Medicine and Community Health, Division of Sports Medicine, University of Hawaii, John A. Burns School \\ of Medicine, Honolulu, Hawaii (Dr Young); Family and Preventive Medicine and Sports Medicine, University of Utah, Salt Lake City, Utah \\ (Dr Campbell); and the University of Hawaii, John A. Burns School of Medicine, Honolulu, Hawaii (Ms Raastad).
}

\begin{abstract}
Wilderness sports and adventures continue to increase in popularity. Counseling is an essential element of the preparticipation evaluation (PPE) for athletes in traditional sports. This approach can be applied to and augmented for the wilderness athlete and adventurer. The authors reviewed the literature on counseling during PPEs and gathered expert opinion from medical professionals who perform such PPEs for wilderness sports enthusiasts. The objective was to present findings of this review and make recommendations on the counseling component of a wilderness sports/adventure PPE. The counseling component of a PPE for wilderness sports/adventures should take place after a basic medical evaluation, and include a discussion on sport or activity-specific injury prevention, personal health, travel recommendations, and emergency event planning. Counseling should be individualized and thorough, and involve shared decision making. This should take place early enough to allow ample time for the athlete or adventurer to further prepare as needed based on the recommendations. Resources may be recommended for individuals desiring more information on selected topics.
\end{abstract}

Key words: preparticipation evaluation, counseling, safety, trip preparation

\section{Background}

Many traditional sports institutions such as high schools, colleges, or professional teams subject athletes to routine sports physical examinations, otherwise known as preparticipation evaluation (PPEs). During such PPEs, counseling for risk reduction based on sport-specific issues and personal health status is the final component. These PPEs are not intended to disqualify a participant; rather they are intended to reduce morbidity and mortality during participation. Preparticipation evaluations were found to actually disqualify less than $1 \%$ of individuals among high schoolers. ${ }^{1}$ As in traditional or organized sports, it is likely also rare to disqualify or recommend an individual not be cleared for a wilderness sport or adventure.

The authors report no conflicts of interest.

This article appears in a "Care of the Wilderness and Adventure Athlete" special issue, jointly published by Clinical Journal of Sport Medicine and Wilderness \& Environmental Medicine.

Corresponding Author: Justin Mark J. Young, MD, Straub Clinic \& Hospital, 888 S. King St, Honolulu, Hawaii 96813 (e-mail: jmjuyoun@hawaii.edu).
Some studies question the overall validity of the PPE on the effect of morbidity and mortality. ${ }^{2-4}$ Although these studies have been focused on team and high school sports, reasons included lack of process standardization and too many entities using differing forms and requirements, making it difficult to formally evaluate. However, despite a lack of evidence, traditional PPEs are both widely performed and required. ${ }^{1}$

Guidelines and recommendations for counseling during PPEs in traditional or organized sports are readily available. PPE: Preparticipation Physical Evaluation, Fourth Edition is considered a comprehensive resource for clinicians evaluating high school and college athletes and is supported by more than 6 major medical societies. ${ }^{1}$ Broad elements from this monograph may be applied to wilderness sports and adventures, but given the unique environments in which wilderness sports/ adventures typically occur, elements of the counseling aspect need to be modified. ${ }^{5}$

When looking exclusively at the collegiate athlete during a PPE, the medical history contributes the greatest component and could lead to a diagnosis of up to $88 \%$ of 
medical conditions. ${ }^{6}$ Given the value of a thorough history, it is likely that the history component of a PPE directed to the wilderness athlete/adventurer would also yield significant information on health conditions and diagnoses. It is this history combined with the sport/ adventure specifics that will guide the counseling component.

Many participants of wilderness sports/adventures will likely not specifically seek counseling but may present to their medical provider for a general physical examination or other isolated need before embarking upon a wilderness sport/ adventure. In other cases, an individual may be asked to obtain a PPE, for example, if using a guided organization for an event or expedition. Any of these situations serve an ideal opportunity for counseling.

\section{Methods}

The following databases were searched: MEDLINE and Cochrane Database of Systematic Reviews. Articles were limited to those printed in English between 1983 and May 2014. Key terms included preparticipation physical examination, preparticipation physical evaluation, PPE and wilderness sports, and wilderness athlete. These terms were cross-matched with the term "counseling." This process yielded over 300 published manuscripts, which were narrowed to over 20 articles, in addition to several books along with expert opinion from wilderness medicine and sports medicine societies for use in this article.

\section{Findings}

Although little information is available on strategies for generalized counseling during a PPE for the wilderness athlete/ adventurer, the literature does contain recommendations for specific wilderness sports or activities, such as in the pediatric athlete, and for individuals with asthma. ${ }^{7-9}$ It is estimated that roughly $50 \%$ of international travelers to a developing country will experience some sort of problem during a one-month trip. ${ }^{10}$ Counseling for travel abroad is available, but counseling specific to wilderness sports/adventures is not readily available. ${ }^{10,11}$

Injury during wilderness sports/adventures is common. On a 23-day alpine Colorado Outward Bound course, more than $85 \%$ of participants sustained some sort of injury while hiking above 10000 feet elevation. ${ }^{12}$ Although most injuries in this study were reported as mild, $10 \%$ to $38 \%$ of the injuries were categorized as severe. Other studies echo this rate of injury. Crouse and Health found that in backpackers who completed hiking the Appalachian Trail, $82 \%$ of participants reported illness or injury of which $25 \%$ of individuals had injuries severe enough to end their trip to seek medical attention. $^{13}$

National Park Service (NPS) data demonstrate increasing utilization of national parks in the United States. ${ }^{14}$ For example, the number of climbers attempting to summit Mount McKinley in Denali national park have increased from 533 in 1979 to 1223 in $2012 .{ }^{15}$ This increase in wilderness participation has been associated with an increase in search and rescue (SAR) activity. The Denali NPS reports 12337 SAR operations from 2003 and 2006. ${ }^{16}$ Injuries and illness on Denali leading to NPS intervention are also prevalent, where McIntosh et al, ${ }^{17}$ describe medical events on Denali across a 20 year time period.

\section{Discussion}

Identifying an individual's risk factors for participation in wilderness sports/adventures is the essence of the counseling component of this type of PPE. Individual demographics, the presence of acute or chronic health conditions, history of previous injury or illness during participation in a wilderness sport/adventure, and environment-specific conditions of the activity should be documented. Using the model of shared decision making can improve an individual's participation in a risk reduction plan and promote safety to avoid accidents. ${ }^{18}$ Table 1 lists some sample questions to discuss with the wilderness athlete/adventurer.

Additional components of counseling for wilderness sports/adventure PPEs include discussing physical fitness and activity-specific conditioning, mental preparation (understanding one's environment and risks), and equipment preparation (proper clothing and gear based on an environment or climate). ${ }^{18}$

Although a standardized PPE for wilderness sports/ adventures does not exist, the baseline goals are the same as PPE models for traditional sports. Counseling should take into account the event location and extent of travel, specific activity or combination of activities, trip duration, and the patient's overall health. Because of the potential for extreme conditions in wilderness

Table 1. Questions to ask during a wilderness sports/ adventure PPE

1. What are your travel plans?

2. Will medical support be available or will you need to provide on your own?

3. How long will your event/adventure last?

4. What environmental hazards do you anticipate?

5. What is your rescue plan if you are injured? 
environments, wilderness sports PPEs will be quite different from high school or other traditional sport PPEs. Building upon these same principles, however, the authors feel using a PPE before a wilderness sport/ adventure has potential to impact morbidity and mortality in wilderness environments as well. Such a PPE, as in high school or traditional sports, should be to optimize health and establish risk based on an individual's health status, where it is likely self-selection that will be the primary motive for attrition.

\section{CLEARANCE ISSUES}

In a PPE for traditional or organized sports, participants would be given a final recommendation of "cleared for full participation without restrictions," "cleared with restrictions," or "not cleared." Wilderness sports/adventures are not typically governed by an entity as in traditional sports. Therefore clearance is not an applicable concept. The term "optimization" may be better suited for wilderness sports/ adventures. If concerns about health and safety during participation exist, temporarily delaying a recommendation to participate may be made. Individuals with poorly controlled disease or acute exacerbations should be appropriately managed through this phase to achieve stability before effective counseling can take place. This may involve a specialty consultation. Medical records should be obtained if an individual does not have an established relationship with the evaluating clinician or if they were referred to a clinician trained in conducting PPEs for wilderness sports/adventures.

Presumably, individuals with stable chronic health conditions can safely participate in wilderness sports. Doan and Luks $^{9}$ present a comprehensive review article making excellent recommendations on pretravel evaluation for individuals with asthma during scuba and altitude expeditions. They recommend persons with asthma make sure they have appropriate inhalers for daily control as well as rescue medication, and go on to provide a comprehensive management plan for acute exacerbations from evidence-based data.

\section{MEDICATIONS}

Individuals with a chronic condition may be taking medications. Participants should be advised to take their own medication kit. $^{19,20}$ The individual should have enough of their own medication for the entire duration of the trip without running out and a few extra days to allow for delays in travel for unexpected reasons. Chronic medications should be refilled and dosing adjusted as indicated by their own primary care provider. ${ }^{21}$ Utilization of a problem list approach that links medications and stability of chronic issues may be helpful to avoid missing important areas. A review of an individual's medication list including over-the-counter medications, supplements, and herbal remedies should occur, with an emphasis on avoiding polypharmacy, and ensuring appropriate dosing and frequency instructions. Medications that can be used for multiple conditions are preferable to those used for only one problem. Table 2 offers suggestions of classes of medications to consider.

Traveling in wilderness environments often means possible limited access to common medications and supplies. Participants should be advised to look into local resources for last minute needs upon arrival at destinations before entering the wilderness. Depending on the participant's medical training, medications might include commonly used things such as antibiotic topical cream, antiseptics, over-the-counter analgesics, antidiarrheal medication, antihistamine, and antacids. ${ }^{7}$

Analgesics and pain control discussions will be valuable to the participant. Controlled substances carry both legal and health risks and should not be used unless specifically counseled on use before travel. The Wilderness Medicine Society (WMS) practice guidelines recommend the combination of acetaminophen with an nonsteroidal antiinflammatory drug (NSAID) as the first line of treatment for acute pain management in the wilderness. ${ }^{22}$

Table 2. Possible items to consider for a medical kit (not intended to be comprehensive, must be individualized)

\begin{tabular}{lll}
\hline Medical Supplies & \multicolumn{1}{c}{ Medications } & Personal Care/Sanitation \\
\hline & & Sunscreen \\
Tape & Pain control & Hand sanitizer \\
Bandages & Antibiotics & Lighter \\
Tourniquet & Antidiarrheal & Hygiene/toiletries \\
Cleaning agents/antiseptic & Antiemetics & Knives \\
Suture/glue materials & Antihistamines & Insect repellant \\
& Topical hydrocortisone & Sunglasses \\
& Personal chronic medications & Hydration/nutrition \\
\hline
\end{tabular}




\section{MEDICAL SUPPLIES}

A medical kit should be lightweight and reasonable to carry, taking only essentials, and whenever possible items that can serve more than one purpose. Consideration of shared group supplies, whenever possible, will avoid redundancy and carrying less-versatile items. Other important considerations include access to clean drinking water and availability of noncontaminated foods. Water purification devices or purifying agents may be included in a medical kit, and sunscreen, insect repellant, topical antiseptic ointment, and personal sanitary supplies. Table 2 summarizes common supplies to consider.

For participants of guided expeditions, the authors recommend the individual become aware of any needed medical supplies and the medical training of the guides with the agency. Often a guided agency will require guides be certified with Wilderness First Responder (WFR) or Emergency Medical Technician (EMT) training, and the guides will most likely carry a basic trip-specific medical kit and have knowledge on how to use it. Participants should be informed not to expect guides to provide medications, and that provision of medical care is on a voluntary basis using "Good Samaritan” parameters. ${ }^{23,24}$

\section{ENVIRONMENT AND TRAINING}

Each respective environment commands the participant have appropriate personal protective gear. Layering is essential in cold environments to protect from frostbite or cold exposure, and hot environments may demand both sun protection and cooling options. ${ }^{25}$ Considerations of hot or cold environments in wilderness sports/adventures are discussed elsewhere, as are issues specific to water sports and altitude. ${ }^{26,27}$ Specifics on training should be directed to personal trainers and clinicians versed in this subject. In addition, excellent books are available for training and conditioning for climbing and alpinism, and for specific techniques on training for altitude sports. ${ }^{28,29}$

\section{INTERNATIONAL TRAVEL AND VACCINATIONS}

Participating in wilderness sports/adventures internationally can have unique issues specific to a geographic region. Ample time before an event is essential so that necessary medications and special supplies can be obtained. ${ }^{30-32}$ International travelers should begin pretravel medical preparation at least 4 to 6 months (Figure) before their date of departure, being aware that Hepatitis A \& B schedules can take even longer than that time

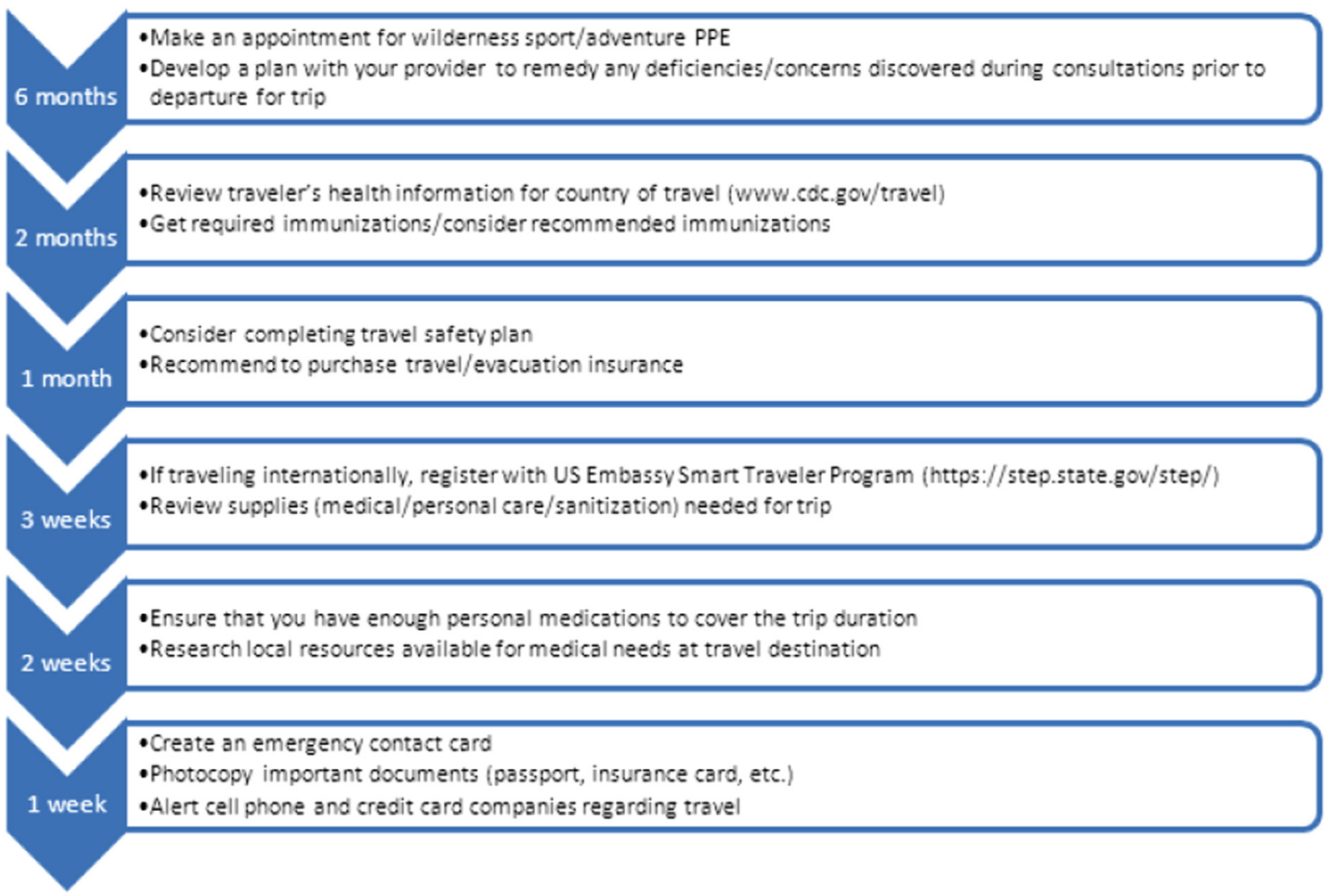

Figure. Recommended predeparture timeline. 
frame to be completed. Moreover, advanced planning and consultation with a travel medicine-trained specialist may be recommended depending on the travel needs. The authors recommend any prospective traveler consult the Centers for Disease Control and Prevention (CDC) Web site (www.cdc.gov) for current vaccination recommendations regarding a specific destination, as well as his/her own physician. ${ }^{30}$

\section{EVACUATION AND EXTRICATION CONSIDERATIONS}

Wilderness sports/adventures are unique based on the often remote and austere nature of the environments. As such, emergency and rescue planning is imperative. Participants should be advised to learn any skills needed for participation in a wilderness sport/adventure as well as to seek out additional training or education on selfrescue. Wilderness environments often do not have adequate access for formal rescue operations or may be too dangerous to rescue personnel, meaning that the individual may be isolated in such a situation. Extrication from remote or extreme environments may pose serious financial consequences to the athlete/adventurer. Because of these costs, rescue insurance plans do exist, and participants in remote areas are encouraged to consider purchasing such a plan. These plans are commercially available and can cover a certain portion of medical costs and some of the cost of rescue, should it be needed. Several plans specialize in the wilderness athlete and may be described by the insurance company as "adventure sports insurance.",33

\section{Summary}

The counseling portion of a wilderness sports/adventure PPE involves understanding of a wilderness athlete/ adventurer's health conditions and issues specific to a given wilderness environment. Counseling strategies from PPEs for traditional/organized sports can serve as the backbone for counseling for wilderness sports/ adventures, but need be modified to include specifics to the wilderness environment and risks posed to an individual in that environment given their health status. The counseling component involves medical optimization for a desired activity by ensuring the stability of chronic health conditions, recommending appropriate medical supplies, medications, and vaccinations. Adventure or travel health insurance for going abroad should be discussed and resources offered. Allowing adequate time in advance of a wilderness sport/adventure can improve a participant's ability to condition and prepare for a wilderness sport/adventure. The participant should be counseled to fully understand any environmental issues, including self-rescue. Future studies can be directed toward the effectiveness of injury prevention after successful counseling.

\section{References}

1. American Academy of Pediatrics, American College of Sports Medicine and American Academy of Family Physicians. PPE: Preparticipation Physical Evaluation. 4th ed. Elk Grove Village, IL: American Academy of Pediatrics; 2010

2. Wingfield K, Matheson GO, Meeuwisse WH. Preparticipation evaluation. Clin J Sport Med. 2004;14:109-122.

3. DuRant RH, Pendergrast RA, Seymore C, et al. Findings from the preparticipation athletic examination and athletic injuries. Am J Dis Child. 1992;146:85-91.

4. Carek P, Mainous A. The preparticipation physical examination for athletics: a systematic review of current recommendations. BMJ. 2003:661-664.

5. Friedewald VE Jr, Spence DW. Sudden cardiac death associated with exercise: the risk-benefit issue. Am J Cardiol. 1990;66:183-188.

6. Chun J, Haney S, DiFiori J. The relative contributions of the history and physical examination in the preparticipation evaluation of collegiate student-athletes. Clin J Sport Med. 2006;16:434-449.

7. Gentile D, Kennedy B. Wilderness medicine for children. Pediatrics. 1991;88:976-981.

8. Stauffer WM, Konop RJ, Kamat D. Traveling with infants and young children. Part I: anticipatory guidance: travel preparation and preventive health advice. J Travel Med. 2001;8:254-259.

9. Doan D, Luks AM. Wilderness and adventure travel with underlying asthma. Wilderness Environ Med. 2014;25: 231-240.

10. Spira AM. Travel medicine I: preparing the traveller. Lancet. 2003;361:1368-1382.

11. Carroll B, Daniel A, Behrens R. Travel health. Part 1: preparing the tropical traveller. Br J Nurs. 2008:17:10461052.

12. Twombly S, Schussman L. Gender differences in injury and illness rates on wilderness backpacking trips. Wilderness Environ Med. 1995;6:363-376.

13. Crouse B, Josephs D. Health care needs of Appalachian trail hikers. J FamPract. 1993;36:521-525.

14. Mort A, Godden D. Injuries to individuals participating in mountain and wilderness sports: a review. Clin J Sport Med. 2011;21:530-536.

15. Mount McKinley South Peak (20, 320 feet) Attempts and Summits. US National Park Service. From files Denali National Park Preservation. Talkeetna Ranger Station. Web site. http://www.nps.gov/dena/planyourvisit/summar yreports.htm. Accessed October 19, 2014.

16. Hultgren HN, Honigman B, Theis K, et al. High-altitude pulmonary edema at a ski resort. West J Med. 1996; 164:222-227. 
17. McIntosh SE, Campbell A, Weber D, et al. Mountaineering medical events and trauma on Denali, 1992-2011. High Alt Med Biol. 2012;13:275-280.

18. Singletary E, Markenson DS. Injury Prevention: Decision Making, Safety, and Accident Avoidance. In: Auerbach PS, ed. Wilderness Medicine. 6th ed. Philadelphia, PA: Elsevier Inc; 2012:334-354.

19. Lewin M, Jensen S, Platts-Mills T. Wilderness preparation, equipment, and medical supplies. In: Auerbach PS, ed. Wilderness Medicine. 6th ed. Philadelphia, PA: Elsevier Inc; 2012:1820-1844.

20. Forgey WW. ed. Wilderness Medical Society Practice Guidelines for Wilderness Emergency Care. In: 5th ed. Guilford, CT: Globe Pequot; 2006.

21. Shandera WX. Travel-related diseases: injury and infectious disease prevention. J Wilderness Med. 1993;4:40-61.

22. Russell KW, Scaife CL, Weber DC, et al. Wilderness Medical society practice guidelines for the treatment of acute pain in remote environments. Wilderness Environ Med. 2014;25:41-49.

23. Burdick TE. Wilderness event medicine: planning for mass gatherings in remote areas. Travel Med Infect Dis. 2005; 3:249-258.

24. Brown R. Outdoor law: the Applicability of Good Samaritan laws to those trained in the Wilderness. Web site. https://www.wildmed.com/articles-resources/. Accessed November 1, 2014.

25. Lipman GS, Eifling KP, Ellis M, et al. Wilderness Medical Society practice guidelines for the prevention and treatment of heat-related illness. Wilderness Environ Med. 2013;24:351-361.

26. Luks AM, McIntosh SE, Grissom CK, et al. Wilderness Medical Society consensus guidelines for the prevention and treatment of acute altitude illness. Wilderness Environ Med. 2010;21:146-155.

27. McIntosh SE, Hamonko M, Freer L, et al. Wilderness Medical Society practice guidelines for the prevention and treatment of frostbite. Wilderness Environ Med. 2011;22: 156-166.

28. House S, Johnston S. Training for the New Alpinism: A Manual for the Climber as an Athlete. Ventura. CA: Patagonia Books; 2014.

29. Schoene R. Training for the wilderness adventure. In: Auerback P, ed. Wilderness Medicine. 6th ed. Philadelphia, PA: Elsevier Inc; 2012:1928-1936.

30. CDC. Traveler's health. Web site. http://wwwnc.cdc.gov/ travel/destinations/list. Accessed October 19, 2014.

31. Zuckerman JN, Van Damme P, Van Herck K, et al. Vaccination options for last-minute travellers in need of travel-related prophylaxis against hepatitis A and B and typhoid fever: a practical guide. Travel Med Infect Dis. 2003;1:219-226.

32. Brunette GW, ed. CDC Health Information for International Travel 2012: The Yellow Book: The Yellow Book. New York, NY: Oxford University Press; 2011.

33. Adventure Sport Insurance. Web site. http://www.imglobal. com/en/img-insurance/adventure-sports-insurance.aspx. Accessed November 1, 2014. 